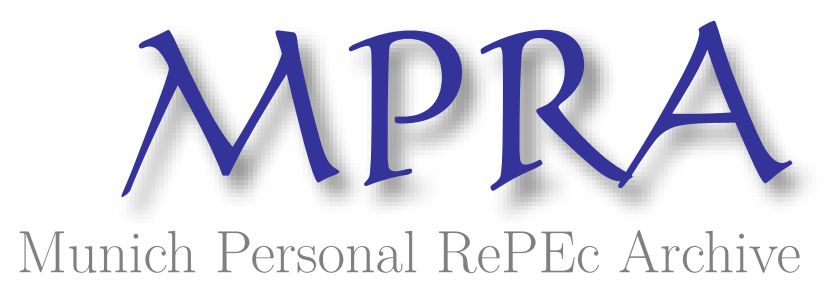

\title{
On the optimal mix of patent instruments
}

Chu, Angus C. and Furukawa, Yuichi

Shanghai University of Finance and Economics, Chukyo University

August 2010

Online at https://mpra.ub.uni-muenchen.de/24039/

MPRA Paper No. 24039, posted 30 Jul 2010 14:35 UTC 


\title{
On the Optimal Mix of Patent Instruments
}

\author{
Angus C. Chu, Shanghai University of Finance and Economics \\ Yuichi Furukawa, Chukyo University
}

August 2010

\begin{abstract}
A special characteristic of the patent system is that it features multiple patent-policy levers that can be employed by policymakers. In this study, we develop a quality-ladder model to analyze the optimal mix of patent instruments. Specifically, we consider (a) patent breadth and (b) the division of profit in research joint ventures. We analytically derive optimal patent policies and then calibrate the model to quantitatively evaluate the welfare gain from optimizing both patent instruments as compared to optimizing only one patent instrument. In summary, we find that the welfare gain can be substantial.
\end{abstract}

JEL classification: O31, O34

Keywords: R\&D, innovation, intellectual property rights

Chu: Shanghai University of Finance and Economics, China. Email: angusccc@gmail.com. Furukawa: Chukyo University, Nagoya, Japan. Email: you.furukawa@gmail.com. 


\section{Introduction}

A special characteristic of the patent system is that it is a multi-dimensional policy system in the sense that it features multiple patent-policy levers, such as patent length and patent breadth, that can be employed by policymakers. Given this notable feature of the patent system, we develop a quality-ladder model to analyze the optimal mix of patent-policy levers. In this study, we consider two patent instruments, namely, patent breadth and a profit-division rule in research joint ventures (RJVs). Our results can be summarized as follows. In the theoretical analysis, we analytically derive the optimal mix of patent breadth and the profit-division rule. Then, in the quantitative analysis, we numerically evaluate the welfare gain from choosing both patent instruments optimally as compared to choosing only patent breadth optimally given any profit-division rule. We find that the welfare gain can be as large as $5 \%$ of consumption per year.

RJVs have been an important focus of some policy reforms that we briefly discuss here, and some of these reforms involve multiple patent-policy levers. The importance of RJVs was firstly emphasized by Penrose (1959) who argue that forming RJVs is a useful way for firms to gain access to external complementary technological resources for R\&D. For example, in order to foster a more cooperative research environment in the US, policymakers enacted the National Cooperative Research Act of 1984 "to promote research and development, encourage innovation, stimulate trade, and make necessary and appropriate modifications in the operation of the antitrust laws." 1 Another example is the Third Amendment to the Chinese Patent Law that was approved in December 2008 and came into effect in October 2009. ${ }^{2}$ One purpose of this patent reform is to encourage the exploitation of jointly owned patents. For example, "Article 15 provides that the exploitation of patent rights between co-owners should be determined by an agreement. Where an agreement is not available, any co-owner may exploit the patent alone or grant general licenses (i.e., non-exclusive licenses) to others to exploit the patent, and that any licensing fee received shall be shared between the co-owners." 3 In our theoretical analysis, we model this patent-policy lever using a profit-

\footnotetext{
${ }^{1}$ This act was subsequently expanded into the National Cooperative Research and Production Act of 1993.

${ }^{2}$ See, for example, Yang and Yen (2010) for a review of the patent-policy changes in this amendment.

${ }^{3}$ See Yang and Yen (2010, p. 8).
} 
division rule in RJVs. In addition to encouraging the exploitation of jointly owned patents, this patent reform also involves other policy changes, such as increasing statutory damages and administrative fines, and heightening patentability requirement. In other words, this policy amendment involves the reform of multiple patent-policy levers instead of a single patent-policy lever. A contribution of the present study is to use a quality-ladder model to demonstrate the welfare difference between optimizing multiple patent instruments and optimizing a single patent instrument.

This study relates to the patent-design literature. In his seminal study, Nordhaus (1969) characterizes optimal patent length and shows that it balances between the social benefit of innovation and the social cost of monopolistic distortion. However, Nordhaus only considers patent length as the single patent-policy lever. Subsequent studies by Tandon (1982), Gilbert and Shapiro (1990), Klemperer (1990) and Denicolo (1996) analyze the optimal mix of patent instruments, such as patent length, patent breadth and compulsory licensing. ${ }^{4}$ The present study complements these interesting partialequilibrium analyses by revisiting the optimal mix of patent instruments in a quantitative dynamic general-equilibrium (DGE) framework, which allows for an explicit consideration of economic growth and social welfare.

In the literature on patent policy and economic growth, the seminal DGE analysis on optimal patent length is Judd (1985), who shows that the optimal patent length can be infinite in a specific environment. In contrast, Futagami and Iwaisako (2007) show that the optimal patent length is usually finite in the Romer model. While these studies focus on patent length, other studies analyze the growth and welfare effects of other patent instruments in R\&D-based growth models. See, for example, Cozzi (2001) on intellectual appropriability, Li (2001) on lagging patent breadth, O'Donoghue and Zweimuller (2004) on leading patent breadth and patentability requirement, Furukawa (2007) on patent protection against imitation, and Chu (2009) on blocking patents. The present paper complements these studies by analyzing the optimal mix of multiple patent instruments, which is often neglected in this literature. ${ }^{5}$

The rest of this study is organized as follows. Section 2 describes the model. Section 3 defines the equilibrium and characterizes the equilibrium

\footnotetext{
${ }^{4}$ See Scotchmer (2004) for a comprehensive review of this patent-design literature.

${ }^{5}$ A notable exception is Iwaisako and Futagami (2003). However, their study is qualitative in nature while the present study also provides a quantitative analysis.
} 
allocation. Section 4 derives optimal patent policies and calibrates the model to provide a quantitative analysis. The final section concludes.

\section{The model}

To consider the optimal mix of patent-policy levers, we modify the GrossmanHelpman (1991) quality-ladder model by incorporating into the model (a) patent breadth that determines the markup and (b) competitive RJVs in which the division of profit is subject to a profit-division rule. In their seminal study, Kamien et al. (1992) define a competitive RJV as an interfirm arrangement in which each firm decides its own $R \& D$ investment taking the other firm's R\&D investment as given and the firms share their innovation. ${ }^{6}$ We adopt this setup to reformulate the R\&D sector of the Grossman-Helpman model. ${ }^{7}$ Given that the quality-ladder model has been well-studied, we briefly describe the familiar features to conserve space and discuss the new features in more details.

\subsection{Households}

There is a unit continuum of identical households. Their lifetime utility is given by

$$
U=\int_{0}^{\infty} e^{-\rho t} \ln C_{t} d t,
$$

where $\rho>0$ is discount rate, and $C_{t}$ is the consumption of final goods at time $t$. Households maximize utility subject to asset accumulation given by

$$
\dot{A}_{t}=R_{t} A_{t}+W_{t}-P_{t} C_{t}
$$

$P_{t}$ denotes the price of final goods at time $t$. Each household supplies one unit of labor (chosen as the numeraire) to earn the wage $W_{t}$ (normalized to

\footnotetext{
${ }^{6}$ See also Greenlee (2005) for an interesting analysis on competitive RJVs.

${ }^{7}$ See also Cozzi (1999) and Cozzi and Tarola (2006) for an interesting analysis on cooperative RJVs in R\&D-based growth models.
} 
unity). $A_{t}$ is the value of assets owned by households, and $R_{t}$ is the nominal rate of return. The familiar Euler equation is

$$
\dot{E}_{t} / E_{t}=R_{t}-\rho
$$

where $E_{t} \equiv P_{t} C_{t}$ is the nominal expenditure on consumption.

\section{$2.2 \quad$ Final goods}

Final goods are produced by a standard Cobb-Douglas aggregator over a unit continuum of differentiated intermediate goods $X_{t}(i)$ indexed by $i \in[0,1]$.

$$
Y_{t}=\exp \left(\int_{0}^{1} \ln X_{t}(i) d i\right) \text {. }
$$

This sector is perfectly competitive, and final-goods firms take both the out-

put and input prices as given. From standard cost minimization, the price index of final goods can be expressed as

$$
P_{t}=\exp \left(\int_{0}^{1} \ln P_{t}(i) d i\right),
$$

where $P_{t}(i)$ is the price of $X_{t}(i)$. The conditional demand curve for $X_{t}(i)$ is

$$
X_{t}(i)=P_{t} Y_{t} / P_{t}(i)
$$

\subsection{Intermediate goods}

There is a unit continuum of differentiated intermediate goods indexed by $i \in[0,1]$. Each intermediate goods $i$ is produced by a monopolistic leader, who holds a patent on the latest innovation. This industry leader dominates the market temporarily until the arrival of the next innovation (i.e., the Arrow replacement effect). ${ }^{8}$ The production function for the leader of intermediate goods $i$ is

$$
X_{t}(i)=z^{q_{t}(i)} L_{t}(i)
$$

\footnotetext{
${ }^{8}$ See Cozzi (2007) for a discussion on the Arrow effect in the quality-ladder model.
} 
The parameter $z>1$ is the step size of a productivity improvement, and $q_{t}(i)$ is the number of productivity improvements that have occurred in industry $i$ as of time $t . L_{t}(i)$ is the number of production workers employed in industry $i$. Given $z^{q_{t}(i)}$, the industry leader's marginal cost of production is

$$
M C_{t}(i)=W_{t} / z^{q_{t}(i)} .
$$

We follow the standard approach in the literature to consider Bertrand competition. Under Bertrand competition, the profit-maximizing price for the current leader is a markup over the marginal cost.

$$
P_{t}(i)=\mu_{t} M C_{t}(i)
$$

where $\mu_{t}=z^{b_{t}}$ and $b_{t}$ is the level of patent breadth at time $t$. Grossman and Helpman (1991) assume complete patent protection against imitation (i.e., $\left.b_{t}=1\right)$. Li (2001) generalizes the patent regime to allow for incomplete patent protection (i.e., $\left.b_{t} \in(0,1)\right)$. Because of incomplete protection, the current leader's innovation enables the former leader to increase her productivity by a factor of $z^{1-b_{t}}$ without infringing the current leader's patent. Therefore, the limit-pricing markup for the current leader is $z^{b_{t}}$. O'Donoghue and Zweimuller (2004) refer to $b_{t} \in(0,1)$ as lagging patent breadth (i.e., backward protection against imitation), and they also consider leading patent breadth $b_{t} \in\{2,3, \ldots\}$, which captures forward protection against subsequent innovation. We follow the formulation in O'Donoghue and Zweimuller (2004) here. In the presence of leading breadth, a profit-sharing arrangement between generations of patentholders is needed, and we consider the optimal frontloading profit-sharing arrangement that is to allow the most recent innovator to obtain all the profits. ${ }^{9}$ Combining lagging breadth and leading breadth with the frontloading profit-sharing arrangement, $b_{t} \in(0, \infty)$ simply becomes a continuous variable. ${ }^{10}$ A larger patent breadth enables the current leader to

\footnotetext{
${ }^{9}$ See O'Donoghue and Zweimuller (2004) and Chu (2009) for a more detailed discussion. In the present study, it is appropriate to consider the frontloading profit-sharing arrangement because our focus is on optimal patent policies.

${ }^{10}$ Let's consider an example of $b_{t}=1.5$ for illustration. In this case, the integer 1 refers to the degree of leading breadth, and the decimal 0.5 refers to the degree of lagging breadth. A leading breadth of degree one implies that the most recent innovator infringes the patent of the second-most recent innovator, and they consolidate their market power giving rise to a markup of $z^{2}$ if lagging breadth were complete. However, an incomplete lagging breadth of 0.5 implies that the third-most recent innovator is able to imitate half
} 
charge a higher markup, and the resulting increase in profit improves incentives for R\&D. For the rest of this study, we use $\mu_{t}$ to denote patent breadth for convenience and consider changes in $\mu_{t}$ coming from changes in $b_{t}$ only. Finally, the amount of monopolistic profit is

$$
\Pi_{t}(i)=\left(\frac{\mu_{t}-1}{\mu_{t}}\right) P_{t}(i) X_{t}(i)=\left(\frac{\mu_{t}-1}{\mu_{t}}\right) P_{t} Y_{t}
$$

for $i \in[0,1]$, and the second equality of (10) follows from (6).

\subsection{R\&D joint ventures}

Denote $V_{t}(i)$ as the value of the latest innovation in industry $i$. Because $\Pi_{t}(i)=\Pi_{t}$ for $i \in[0,1]$ from $(10), V_{t}(i)=V_{t}$ in a symmetric equilibrium that features an equal arrival rate of innovation across industries. ${ }^{11}$ The familiar no-arbitrage condition for $V_{t}$ is

$$
R_{t} V_{t}=\Pi_{t}+\dot{V}_{t}-\lambda_{t} V_{t}
$$

which equates the interest rate to the asset return per unit of asset. The asset return is the sum of (a) the profit $\Pi_{t}$ received by the patentholder, (b) the potential capital gain $\dot{V}_{t}$, and (c) the expected capital loss due to creative destruction $\lambda_{t} V_{t}$, where $\lambda_{t}$ is the industry-level Poisson arrival rate of innovation.

Greenlee (2005) provides a survey of empirical evidence to show that firms in RJVs tend to behave competitively rather than cooperatively. Therefore, we consider competitive RJVs and assume that a successful innovation requires R\&D inputs from two types of entrepreneurs, which we label as type-1 and type- 2 entrepreneurs. This formulation is also consistent with the empirical evidence summarized in Greenlee (2005) that "firms perceive gaining access to complementary knowledge as the single most important objective

of the innovation owned by the second-most recent innovator, and the resulting Bertrand competition between the third-most recent innovator and the coalition (formed by the most recent innovator and the second-most recent innovator) pushes the markup down to $z^{1.5}$.

${ }^{11}$ We follow the standard approach in the literature to focus on the symmetric equilibrium. See Cozzi et al. (2007) for a theoretical justification for the symmetric equilibrium in the quality-ladder model. 
in research consortia." In the economy, there is a unit continuum of each type of entrepreneurs. For simplicity, we consider a Cobb-Douglas functional form for the individual-level arrival rate of innovation. ${ }^{12}$

$$
\widetilde{\lambda}_{t}=\varphi\left(H_{1, t}\right)^{\alpha}\left(H_{2, t}\right)^{1-\alpha},
$$

where $\alpha \in(0,1) .{ }^{13} \quad H_{1, t}$ and $H_{2, t}$ denote R\&D labors employed by type- 1 and type- 2 entrepreneurs respectively.

In the case of a successful innovation, the two entrepreneurs sell the patent to a manufacturer, and they share the value of the patent according to a profit-division rule $s_{t} \in(0,1)$. A type- 1 entrepreneur receives $s_{t} V_{t}$ while a type- 2 entrepreneur receives $\left(1-s_{t}\right) V_{t}$. This division of profit can be viewed as a bargaining outcome, and the bargaining power of each side can be influenced by patent policy. Therefore, it is not unreasonable to treat $s_{t}$ as a policy variable. The expected return to R\&D for a type- 1 entrepreneur is

$$
\pi_{1, t}=s_{t} V_{t} \widetilde{\lambda}_{t}-W_{t} H_{1, t}
$$

and the expected return to $\mathrm{R} \& \mathrm{D}$ for a type- 2 entrepreneur is

$$
\pi_{2, t}=\left(1-s_{t}\right) V_{t} \widetilde{\lambda}_{t}-W_{t} H_{2, t} .
$$

In equilibrium, the first-order conditions for $H_{1, t}$ and $H_{2, t}$ become

$$
\begin{gathered}
\alpha s_{t} V_{t} \lambda_{t}=W_{t} H_{1, t}, \\
(1-\alpha)\left(1-s_{t}\right) V_{t} \lambda_{t}=W_{t} H_{2, t} .
\end{gathered}
$$

Equations (15) and (16) imply that the R\&D sector generates positive profits, which are transferred back to the households. ${ }^{14}$ Combining (15) and (16) yields the equilibrium ratio of $H_{1, t}$ to $H_{2, t}$ given by

$$
\frac{H_{1, t}}{H_{2, t}}=\frac{s_{t}}{1-s_{t}}\left(\frac{\alpha}{1-\alpha}\right) .
$$

\footnotetext{
${ }^{12}$ In an unpublished appendix (see Appendix B), we derive optimal patent policies for the more general CES specification.

${ }^{13}$ In equilibrium, $\lambda_{t}=\widetilde{\lambda}_{t}$.

${ }^{14}$ Therefore, households' assets include patents and the ownership of R\&D enterprises.
} 


\section{Decentralized equilibrium}

The equilibrium is a time path $\left\{C_{t}, Y_{t}, X_{t}(i), L_{t}, H_{1, t}, H_{2, t}, W_{t}, R_{t}, V_{t}, P_{t}, P_{t}(i)\right\}$, $t \geq 0$. Also, at each instant of time,

- households maximize utility taking $\left\{R_{t}, P_{t}, W_{t}\right\}$ as given;

- competitive final-goods firms produce $\left\{Y_{t}\right\}$ to maximize profit taking $\left\{P_{t}, P_{t}(i)\right\}$ as given;

- monopolistic intermediate-goods firms produce $\left\{X_{t}(i)\right\}$ and choose $\left\{P_{t}(i)\right\}$ to maximize profit taking $\left\{W_{t}\right\}$ as given;

- R\&D entrepreneurs choose $\left\{H_{1, t}, H_{2, t}\right\}$ to maximize expected profit taking $\left\{W_{t}, V_{t}\right\}$ as given;

- the labor market clears such that $L_{t}+H_{1, t}+H_{2, t}=1$; and

- the goods market clears such that $Y_{t}=C_{t}$.

\subsection{Equilibrium allocation}

Proposition 1 shows that given a stationary path of patent breadth $\mu$ and profit-division rule $s$, the economy is on a stable and unique balanced-growth path, along which the equilibrium allocation of labor inputs is stationary.

Proposition 1 Given constant $\mu$ and $s$, the economy always jumps to a unique and stable balanced-growth path.

Proof. See Appendix A.

Imposing balanced growth on (11) yields $V_{t}=\Pi_{t} /(\rho+\lambda)$. From (10), the production-labor share of output is $W_{t} L_{t}=P_{t} Y_{t} / \mu$. Substituting these two conditions along with (10) and (12) into (15) yields

$$
\rho+\varphi\left(H_{1}\right)^{\alpha}\left(H_{2}\right)^{1-\alpha}=\alpha s(\mu-1) \varphi\left(\frac{H_{2}}{H_{1}}\right)^{1-\alpha} L .
$$


Combining (17), (18) and the labor-market-clearing condition yields the equilibrium allocation of labor inputs given by

$$
\begin{gathered}
L=\frac{\rho /\left[\varphi s^{\alpha}(1-s)^{1-\alpha} \alpha^{\alpha}(1-\alpha)^{1-\alpha}\right]+1 /[s \alpha+(1-s)(1-\alpha)]}{(\mu-1)+1 /[s \alpha+(1-s)(1-\alpha)]}, \\
H_{1}=\left(\frac{s \alpha}{s \alpha+(1-s)(1-\alpha)}\right)(1-L), \\
H_{2}=\left(\frac{(1-s)(1-\alpha)}{s \alpha+(1-s)(1-\alpha)}\right)(1-L) .
\end{gathered}
$$

To ensure the non-negativity of $\mathrm{R} \& \mathrm{D}$ labors, we impose a lower bound on R\&D productivity $\varphi$, which we label as Condition $R$.

$$
\varphi>\frac{\rho /(\mu-1)}{s^{\alpha}(1-s)^{1-\alpha} \alpha^{\alpha}(1-\alpha)^{1-\alpha}} .
$$

It is useful to note that Condition $R$ implies $L<1$.

Substituting (7) into (4) yields $Y_{t}=Z_{t} L_{t}$, where the aggregate level of technology is defined as

$$
Z_{t} \equiv \exp \left(\int_{0}^{1} q_{t}(i) d i \ln z\right)=\exp \left(\int_{0}^{t} \lambda_{\tau} d \tau \ln z\right),
$$

where the second equality can be obtained by appealing to the law of large numbers. Finally, differentiating the $\log$ of $(22)$ with respect to $t$ yields the growth rate of technology given by $g_{t} \equiv \dot{Z}_{t} / Z_{t}=\lambda_{t} \ln z$.

\section{Optimal mix of patent instruments}

Before we derive the optimal mix of patent breadth and the profit-division

rule, we firstly derive the first-best allocation of labor inputs. Given the balanced-growth behavior of the economy, the lifetime utility of households in (1) can be re-expressed as

$$
U=\frac{1}{\rho}\left(\ln C_{0}+\frac{g}{\rho}\right)
$$


where $g=\lambda \ln z$ and $C_{0}=Z_{0} L$. Maximizing (23) subject to $L+H_{1}+H_{2}=1$ yields the first-best allocations $\left\{L^{*}, H_{1}^{*}, H_{2}^{*}\right\}$.

$$
\begin{gathered}
L^{*}=\frac{1}{\alpha^{\alpha}(1-\alpha)^{1-\alpha}}\left(\frac{\rho}{\varphi \ln z}\right), \\
H_{1}^{*}=\alpha\left(1-L^{*}\right), \\
H_{2}^{*}=(1-\alpha)\left(1-L^{*}\right) .
\end{gathered}
$$

Therefore, to achieve the first-best allocation of labor inputs, we need two policy instruments. In our model, patent breadth serves the purpose of optimizing the relative allocation of production labor $L$ and $\mathrm{R} \& \mathrm{D}$ labors $\left\{H_{1}, H_{2}\right\}$. It is useful to note that a larger patent breadth increases $H_{1}$ and $H_{2}$ but decreases $L$. As for the profit-division rule, it serves the purpose of optimizing the relative allocation of R\&D labors. An increase in $s$ changes the incentives of type- 1 and type- 2 entrepreneurs giving rise to an increase in $H_{1}$ relative to $H_{2}$.

When both patent instruments are chosen optimally, the optimal profitdivision rule is

$$
s^{*}=0.5
$$

regardless of the value for $\alpha \cdot{ }^{15}$ Equations (25) and (26) show that $H_{1}^{*} / H_{2}^{*}=$ $\alpha /(1-\alpha)$, which can be satisfied in (17) if and only if $s=0.5$. Intuitively, the optimal $H_{1}^{*} / H_{2}^{*}$ is solely determined by the relative input share $\alpha /(1-\alpha)$ while the market-equilibrium allocation is determined by the relative division of profit $s /(1-s)$ in addition to the input share. Therefore, to achieve the optimal allocation, the effect of $s /(1-s)$ in the market equilibrium should be eliminated by setting $s /(1-s)=1$. As for optimal patent breadth, equating (19) and (24) and setting $s^{*}=0.5$ yields

$$
\mu^{*}=2\left(\alpha^{\alpha}(1-\alpha)^{1-\alpha} \frac{\varphi}{\rho}+1\right) \ln z-1 .
$$

Proposition 2 When both patent instruments are chosen optimally, the optimal profit-division rule is $s^{*}=0.5$ and optimal patent breadth is given by $\mu^{*}$ in (28). Also, $\mu^{*}$ increases in $\varphi$ and $z$ but decreases in $\rho$.

\footnotetext{
${ }^{15}$ In an unpublished appendix (see Appendix B), we show that this result is robust to generalizing (12) to a CES specification.
} 
Proof. See (27) and (28). At $s^{*}$ and $\mu^{*}$, the equilibrium labor allocations in (19) to (21) coincide with the first-best labor allocations in (24) to (26).

Intuitively, an increase in $\varphi$ or $z$ strengthens the positive effect of $R \& D$ on economic growth, so that $\mu^{*}$ is increasing in $\varphi$ and $z$. In contrast, an increase in $\rho$ reduces the benefit of a higher growth rate on social welfare, so that $\mu^{*}$ is decreasing in $\rho$. Substituting $s^{*}$ and $\mu^{*}$ into $g=(\varphi \ln z)\left(H_{1}\right)^{\alpha}\left(H_{2}\right)^{1-\alpha}$ yields the first-best growth rate given by

$$
g^{*}=(\varphi \ln z) \alpha^{\alpha}(1-\alpha)^{1-\alpha}-\rho .
$$

\subsection{Optimal patent breadth}

In this section, we derive optimal patent breadth for any given $s$. Using (20) and (21), we can rewrite (23) as

$$
U=\frac{1}{\rho}\left[\ln L+\frac{\varphi \ln z}{\rho}\left(\frac{s^{\alpha}(1-s)^{1-\alpha} \alpha^{\alpha}(1-\alpha)^{1-\alpha}}{s \alpha+(1-s)(1-\alpha)}\right)(1-L)\right],
$$

where $Z_{0}$ is normalized to unity, and $L$ is given by (19). Differentiating (30) with respect to $\mu$ yields

$$
\frac{\partial U}{\partial \mu}=\frac{1}{\rho}\left[\frac{1}{L} \frac{\partial L}{\partial \mu}-\frac{\varphi \ln z}{\rho}\left(\frac{s^{\alpha}(1-s)^{1-\alpha} \alpha^{\alpha}(1-\alpha)^{1-\alpha}}{s \alpha+(1-s)(1-\alpha)}\right) \frac{\partial L}{\partial \mu}\right],
$$

where

$$
\frac{\partial L}{\partial \mu}=-\frac{L}{(\mu-1)+1 /[s \alpha+(1-s)(1-\alpha)]} .
$$

Substituting (32) into (31) and setting $\partial U / \partial \mu=0$ yield $\mu^{* *}$, which denotes the optimal patent breadth for any given $s$.

$$
\left.L^{* *} \equiv L\right|_{\mu=\mu^{* *}}=\frac{s \alpha+(1-s)(1-\alpha)}{s^{\alpha}(1-s)^{1-\alpha} \alpha^{\alpha}(1-\alpha)^{1-\alpha}}\left(\frac{\rho}{\varphi \ln z}\right) .
$$

Substituting (33) into $g=(\varphi \ln z)\left(H_{1}\right)^{\alpha}\left(H_{2}\right)^{1-\alpha}$ yields the growth rate at $\mu=\mu^{* *}$.

$$
\left.g^{* *} \equiv g\right|_{\mu=\mu^{* *}}=(\varphi \ln z) \alpha^{\alpha}(1-\alpha)^{1-\alpha} \Phi-\rho,
$$


where $\Phi \equiv s^{\alpha}(1-s)^{1-\alpha} /[s \alpha+(1-s)(1-\alpha)] \leq 1$ is a composite parameter. Comparing (29) and (34) shows that $g^{* *} \leq g^{*}$. Intuitively, without the optimal profit-division rule, the economy allocates too much labor to production (i.e., $L^{* *} \geq L^{*}$ ) and fails to achieve the optimal allocation of R\&D labors $H_{1}$ and $H_{2}$. As a result of the suboptimal allocation of R\&D labors, the economy exhibits a lower growth rate than the first-best allocation.

Proposition 3 Suppose that only the patent breadth is chosen optimally. Then, the equilibrium growth rate would be lower than the case in which both patent instruments are chosen optimally.

Proof. Comparing (29) and (34) shows that $g^{* *} \leq g^{*}$ because $\Phi \leq 1$, which becomes a strict inequality unless $s=s^{*}=0.5$.

As for social welfare, we can derive the welfare difference $\Delta U \equiv U^{*}-U^{* *}$, where $\left.U^{* *} \equiv U\right|_{\mu=\mu^{* *}}$, as follows.

$$
\Delta U=\frac{1}{\rho}\left(\ln \Phi+\frac{(\varphi \ln z) \alpha^{\alpha}(1-\alpha)^{1-\alpha}}{\rho}(1-\Phi)\right) \geq 0
$$

where $\Phi=s^{\alpha}(1-s)^{1-\alpha} /[s \alpha+(1-s)(1-\alpha)] \leq 1$ as defined before; therefore, $\ln \Phi \leq 0$ and $1-\Phi \geq 0$. It can be shown that $\Phi$ is an inverted U-shape function in $s$ and reaches its maximum of one at $s=0.5$. As for the relationship between $\Delta U$ and $\Phi$, differentiating (35) with respect to $\Phi$ shows that

$$
\frac{\partial \Delta U}{\partial \Phi} \leq 0 \Leftrightarrow \Phi \geq \frac{1}{\alpha^{\alpha}(1-\alpha)^{1-\alpha}}\left(\frac{\rho}{\varphi \ln z}\right)
$$

where the second inequality can be re-expressed as

$$
1 \geq \frac{s \alpha+(1-s)(1-\alpha)}{s^{\alpha}(1-s)^{1-\alpha} \alpha^{\alpha}(1-\alpha)^{1-\alpha}}\left(\frac{\rho}{\varphi \ln z}\right)=L^{* *},
$$

which is guaranteed to hold by Condition $R$. Therefore, $\Delta U$ is an U-shape function in $s$ and reaches a minimum of zero at $s=s^{*}=0.5$. 


\subsection{Quantitative analysis}

In this section, we calibrate the model to illustrate quantitatively the welfare gain from choosing both patent instruments optimally as compared to choosing only patent breadth optimally. In Table 1 , we numerically evaluate $\Delta U$ in (35) for $s \in[0.2,0.8]$. We consider $\{\rho, z, \varphi, \alpha\}=\{0.04,1.10,1.15,0.50\}$ as our benchmark parameter values. For easier interpretation, we express the welfare difference in terms of equivalent variation in consumption flow denoted by $\delta \equiv \exp (\rho \Delta U)-1$. More formally, $\delta$ is defined as $U\left(C_{0}^{*}, g^{*}\right)=$ $U\left(C_{0}^{* *}(1+\delta), g^{* *}\right)$.

Table 1: Effects of $s$ on growth and welfare

$\begin{array}{cccccccc}s & 0.2 & 0.3 & 0.4 & 0.5 & 0.6 & 0.7 & 0.8 \\ g^{* *} & 0.4 \% & 1.0 \% & 1.4 \% & 1.5 \% & 1.4 \% & 1.0 \% & 0.4 \% \\ \delta & 5.2 \% & 2.8 \% & 0.7 \% & 0 \% & 0.7 \% & 2.8 \% & 5.2 \%\end{array}$

Table 1 shows that going from optimizing only patent breadth to optimizing both patent instruments can lead to a welfare gain of as large as $5 \%$ of consumption per year. The magnitude of the welfare gain depends on the value of $\varphi$. When we consider a larger (smaller) value of $\varphi$, both the growth rate and the welfare gain become larger (smaller). Given a long-run growth rate of at least $1.5 \%$, we consider a value of 1.15 for $\varphi$ to be conservative.

\section{Conclusion}

In this study, we have developed a simple quality-ladder model to analyze the optimal mix of patent instruments. Even in our simple model, we find that optimizing a single patent instrument is insufficient for the economy to achieve the socially optimal allocation of factor inputs. Therefore, in the more complicated real world, it is unlikely that optimizing a single patent instrument would be sufficient for achieving the social optimum. This finding suggests that future studies on optimal patent protection may want to further explore the multiple dimensionality of the patent system in order for their analysis to be more suitable for policy applications. 


\section{References}

[1] Chu, A., 2009. Effects of blocking patents on R\&D: A quantitative DGE analysis. Journal of Economic Growth 14, 55-78.

[2] Cozzi, G., 1999. R\&D cooperation and growth. Journal of Economic Theory 86, 17-49.

[3] Cozzi, G., 2001. Inventing or spying? Implications for growth. Journal of Economic Growth 6, 55-77.

[4] Cozzi, G., 2007. The Arrow effect under competitive R\&D. The B.E. Journal of Macroeconomics (Contributions) 7, Issue 1, Article 2.

[5] Cozzi, G., Giordani, P., and Zamparelli, L., 2007. The refoundation of the symmetric equilibrium in Schumpeterian growth models. Journal of Economic Theory 136, 788-797.

[6] Cozzi, G., and Tarola, O., 2006. R\&D cooperation, innovation, and growth. Journal of Institutional and Theoretical Economics 162, 683701.

[7] Denicolo, V., 1996. Patent races and optimal patent breadth and length. Journal of Industrial Economics 44, 249-265.

[8] Furukawa, Y., 2007. The protection of intellectual property rights and endogenous growth: Is stronger always better? Journal of Economic Dynamics and Control 31, 3644-3670.

[9] Futagami, K., and Iwaisako, T., 2007. Dynamic analysis of patent policy in an endogenous growth model. Journal of Economic Theory 132, 306334 .

[10] Gilbert, R., and Shapiro, C., 1990. Optimal patent length and breadth. RAND Journal of Economics 21, 106-112.

[11] Greenlee, P., 2005. Endogenous formation of competitive research sharing joint ventures. Journal of Industrial Economics 53, 355 - 391.

[12] Grossman, G., and Helpman, E., 1991. Quality ladders in the theory of growth. Review of Economic Studies 58, 43-61. 
[13] Iwaisako, T., and Futagami, K., 2003. Patent policy in an endogenous growth model. Journal of Economics 78, 239-258.

[14] Judd, K., 1985. On the performance of patents. Econometrica 53, 567586.

[15] Kamien, M., Muller, E., and Zang, I., 1992. Research joint ventures and R\&D cartels. American Economic Review 82, 1293-1306.

[16] Klemperer, P., 1990. How broad should the scope of patent protection be? RAND Journal of Economics 21, 113-130.

[17] Li, C.-W., 2001. On the policy implications of endogenous technological progress. Economic Journal 111, C164-C179.

[18] Nordhaus, W., 1969. Invention, Growth, and Welfare. The MIT Press.

[19] O'Donoghue, T., and Zweimuller, J., 2004. Patents in a model of endogenous growth. Journal of Economic Growth 9, 81-123.

[20] Penrose, E., 1959. The Theory of the Growth of the Firm. Oxford University Press.

[21] Scotchmer, S., 2004. Innovation and Incentives. The MIT Press.

[22] Tandon, P., 1982. Optimal patents with compulsory licensing. Journal of Political Economy 90, 470-486.

[23] Yang, W., and Yen, Y., 2010. The dragon gets new IP claws: The latest amendments to the Chinese patent law. IPO Articles and Reports. 


\section{Appendix A}

Proof of Proposition 1. Substituting (17) into (15) yields

$$
\Gamma V_{t}=W_{t},
$$

where $\Gamma \equiv \varphi s^{\alpha}(1-s)^{1-\alpha} \alpha^{\alpha}(1-\alpha)^{1-\alpha}$ is a composite parameter. Normalizing $W_{t}$ to unity implies that $\dot{V}_{t}=0$ for all $t$. Consequently, (11) becomes

$$
R_{t}=\frac{\Pi_{t}}{V_{t}}-\lambda_{t}
$$

Combining (10) and (A1) yields

$$
\frac{\Pi_{t}}{V_{t}}=\Gamma\left(\frac{\mu-1}{\mu}\right) E_{t} .
$$

Substituting (17) into (12) yields

$$
\lambda_{t}=\varphi\left(\frac{H_{2, t}}{H_{1, t}}\right)^{1-\alpha} H_{1, t}=\varphi\left(\frac{(1-s)(1-\alpha)}{s \alpha}\right)^{1-\alpha} H_{1, t} .
$$

Substituting (17) into the labor-market-clearing condition yields

$$
1=L_{t}+H_{1, t}+H_{2, t}=L_{t}+\left(\frac{s \alpha+(1-s)(1-\alpha)}{s \alpha}\right) H_{1, t} .
$$

Using the production-labor share of output (i.e., $W_{t} L_{t}=E_{t} / \mu$ ), we have

$$
L_{t}=E_{t} / \mu .
$$

Substituting (A2) - (A6) into (3) yields

$$
\frac{\dot{E}_{t}}{E_{t}}=\frac{\Gamma}{\mu}\left(\mu-1+\frac{1}{s \alpha+(1-s)(1-\alpha)}\right) E_{t}-\frac{\Gamma}{\alpha s+(1-\alpha)(1-s)}-\rho .
$$

Equation (A7) implies that the dynamics of $E_{t}$ is characterized by saddlepoint stability such that $E_{t}$ always jumps to its interior steady-state value given by

$$
E=\mu\left(\frac{\rho / \Gamma+1 /[\alpha s+(1-\alpha)(1-s)]}{(\mu-1)+1 /[s \alpha+(1-s)(1-\alpha)]}\right) .
$$

Otherwise, $E_{t}=\mu L_{t}$ approaching zero violates the utility maximization of households while $E_{t}=\mu L_{t}$ approaching $\mu$ violates the profit maximization of R\&D entrepreneurs. Equation (A6) implies that the stationarity of $E_{t}$ ensures the stationarity of $L_{t}$, which in turn ensures the stationarity of $H_{1, t}$ and $H_{2, t}$. 


\section{Appendix B (not for publication)}

In this appendix, we consider a CES specification for $\widetilde{\lambda}_{t}$ given by

$$
\widetilde{\lambda}_{t}=\varphi\left(\alpha H_{1, t}^{\frac{\varepsilon-1}{\varepsilon}}+(1-\alpha) H_{2, \frac{\varepsilon-1}{\varepsilon}}^{\frac{\varepsilon}{\varepsilon}}\right)^{\frac{\varepsilon}{\varepsilon-1}}
$$

Noting (13) and (14), the first-order conditions are

$$
\begin{gathered}
\alpha s V \varphi\left(\alpha H_{1, t}^{\frac{\varepsilon-1}{\varepsilon}}+(1-\alpha) H_{2, t}^{\frac{\varepsilon-1}{\varepsilon}}\right)^{\frac{1}{\varepsilon-1}} H_{1, t}^{-\frac{1}{\varepsilon}}=W_{t}, \\
(1-\alpha)(1-s) V \varphi\left(\alpha H_{1, t}^{\frac{\varepsilon-1}{\varepsilon}}+(1-\alpha) H_{2, t}^{\frac{\varepsilon-1}{\varepsilon}}\right)^{\frac{1}{\varepsilon-1}} H_{2, t}^{-\frac{1}{\varepsilon}}=W_{t}
\end{gathered}
$$

These conditions imply that

$$
\begin{gathered}
\frac{H_{1}}{H_{2}}=\left(\frac{\alpha s}{(1-\alpha)(1-s)}\right)^{\varepsilon}, \\
\frac{W_{t}}{V_{t}}=\varphi\left(\alpha^{\varepsilon} s^{\varepsilon-1}+(1-\alpha)^{\varepsilon}(1-s)^{\varepsilon-1}\right)^{\frac{1}{\varepsilon-1}}, \\
\widetilde{\lambda}_{t}=(1-\alpha)^{-\varepsilon}(1-s)^{-\varepsilon} \varphi\left(\alpha^{\varepsilon} s^{\varepsilon-1}+(1-\alpha)^{\varepsilon}(1-s)^{\varepsilon-1}\right)^{\frac{\varepsilon}{\varepsilon-1}} H_{2, t}, \\
\widetilde{\lambda}_{t}=(\alpha s)^{-\varepsilon} \varphi\left(\alpha^{\varepsilon} s^{\varepsilon-1}+(1-\alpha)^{\varepsilon}(1-s)^{\varepsilon-1}\right)^{\frac{\varepsilon}{\varepsilon-1}} H_{1, t} .
\end{gathered}
$$

Using the labor-market-clearing condition, we can show that

$$
H_{1}+H_{2}=1-L=\frac{\left((\alpha s)^{\varepsilon}+(1-\alpha)^{\varepsilon}(1-s)^{\varepsilon}\right) \lambda}{\varphi\left(\alpha^{\varepsilon} s^{\varepsilon-1}+(1-\alpha)^{\varepsilon}(1-s)^{\varepsilon-1}\right)^{\frac{\varepsilon}{\varepsilon-1}}} .
$$

It is useful to note that $V=\Pi /(\rho+\lambda)$ and $\Pi=E(\mu-1) / \mu=W L(\mu-1)$ hold on the balanced growth path. Therefore,

$$
\rho+\lambda=(\mu-1) \frac{W L}{V}=(\mu-1) L \varphi\left(\alpha^{\varepsilon} s^{\varepsilon-1}+(1-\alpha)^{\varepsilon}(1-s)^{\varepsilon-1}\right)^{\frac{1}{\varepsilon-1}} .
$$

Combining (B8) and (B9), we can determine the rate of innovation $\lambda$ as follows. ${ }^{16}$

$$
\lambda=\frac{\varphi\left(\alpha^{\varepsilon} s^{\varepsilon-1}+(1-\alpha)^{\varepsilon}(1-s)^{\varepsilon-1}\right)^{\frac{1}{\varepsilon-1}}(\mu-1)-\rho}{1+(\mu-1)\left[(\alpha s)^{\varepsilon}+(1-\alpha)^{\varepsilon}(1-s)^{\varepsilon}\right] /\left[\alpha^{\varepsilon} s^{\varepsilon-1}+(1-\alpha)^{\varepsilon}(1-s)^{\varepsilon-1}\right]} .
$$

\footnotetext{
${ }^{16}$ It is useful to note that

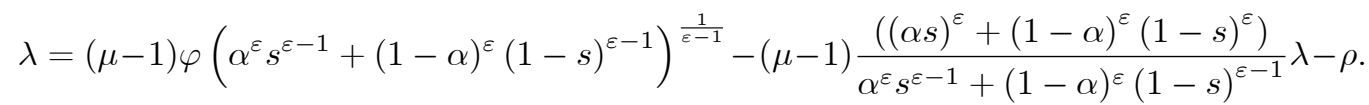


Substituting (B10) into (B6) - (B8) yields

$$
\begin{array}{r}
L=\frac{\rho /\left[\varphi\left(\alpha^{\varepsilon} s^{\varepsilon-1}+(1-\alpha)^{\varepsilon}(1-s)^{\varepsilon-1}\right)^{\frac{\varepsilon}{\varepsilon-1}}\right]+1 /\left[(\alpha s)^{\varepsilon}+(1-\alpha)^{\varepsilon}(1-s)^{\varepsilon}\right]}{(\mu-1) /\left[\alpha^{\varepsilon} s^{\varepsilon-1}+(1-\alpha)^{\varepsilon}(1-s)^{\varepsilon-1}\right]+1 /\left[(\alpha s)^{\varepsilon}+(1-\alpha)^{\varepsilon}(1-s)^{\varepsilon}\right]}, \\
H_{1}=\frac{(\alpha s)^{\varepsilon}}{(\alpha s)^{\varepsilon}+(1-\alpha)^{\varepsilon}(1-s)^{\varepsilon}}(1-L), \\
H_{2}=\frac{(1-\alpha)^{\varepsilon}(1-s)^{\varepsilon}}{(\alpha s)^{\varepsilon}+(1-\alpha)^{\varepsilon}(1-s)^{\varepsilon}}(1-L) .
\end{array}
$$

To calculate the optimal distribution, we will consider

$$
\max U=\frac{1}{\rho}\left(\ln Z_{0}+\ln L+\frac{\lambda \ln z}{\rho}\right)
$$

subject to $L+H_{1}+H_{2}=1$ and $\lambda=\varphi\left(\alpha H_{1}^{\frac{\varepsilon-1}{\varepsilon}}+(1-\alpha) H_{2}^{\frac{\varepsilon-1}{\varepsilon}}\right)^{\frac{\varepsilon}{\varepsilon-1}}$. The solution to this problem gives rise to

$$
\begin{gathered}
L=\frac{1}{\left[\alpha^{\varepsilon}+(1-\alpha)^{\varepsilon}\right]^{1 /(\varepsilon-1)}}\left(\frac{\rho}{\varphi \ln z}\right), \\
H_{1}=\frac{\alpha^{\varepsilon}}{\alpha^{\varepsilon}+(1-\alpha)^{\varepsilon}}(1-L), \\
H_{2}=\frac{(1-\alpha)^{\varepsilon}}{\alpha^{\varepsilon}+(1-\alpha)^{\varepsilon}}(1-L) .
\end{gathered}
$$

Therefore, when both patent instruments are chosen optimally, the optimal profit-division rule continues to be

$$
s^{*}=0.5,
$$

and the optimal patent breadth is

$$
\mu^{*}=2\left(\left[\alpha^{\varepsilon}+(1-\alpha)^{\varepsilon}\right]^{1 /(\varepsilon-1)} \frac{\varphi}{\rho}+1\right) \ln z-1 .
$$

